\title{
Imaging of Secreted Extracellular Periostin, an Important Marker of Invasion in the Tumor Microenvironment in Esophageal Cancer
}

\author{
Pedram Heidari*1, Shadi A. Esfahani*1, Nazife S. Turker ${ }^{1}$, Gabrielle Wong ${ }^{2}$, Timothy C. Wang ${ }^{3}$, Anil K. Rustgi ${ }^{2}$, \\ and Umar Mahmood ${ }^{1}$ \\ ${ }^{I}$ Department of Radiology, Athinoula A. Martinos Center for Biomedical Imaging, Massachusetts General Hospital, Boston, \\ Massachusetts; ${ }^{2}$ Division of Digestive and Liver Diseases, Department of Medicine, Columbia University Medical Center, New York, \\ New York; and ${ }^{3}$ Division of Gastroenterology, Department of Medicine, University of Pennsylvania Perelman School of Medicine, \\ Philadelphia, Pennsylvania
}

Periostin, an extracellular matrix protein, plays key role in cell adhesion and motility within the tumor microenvironment and is correlated with tumor invasion. We developed and characterized a PET tracer that specifically targets periostin and evaluated the probe in preclinical models of esophageal squamous cell carcinoma (ESCC). Methods: The Institutional Animal Care and Use Committee approved all animal studies. Antiperiostin- $F\left(a b^{\prime}\right)_{2}$ was generated from a monoclonal antibody by enzymatic digestion, conjugated to DOTA, and labeled with ${ }^{64} \mathrm{Cu}$. Human ESCC cell lines, TE-11 with high and $\Pi T$ with minimal periostin expression, were implanted in nu/nu mice to generate the positive and control tumor models, respectively. PET/CT imaging was performed at 6,12 , and $24 \mathrm{~h}$ and organ-specific biodistribution at $24 \mathrm{~h}$ after probe injection. Additionally the probe was tested in a genetically engineered mouse model of periostinexpressing distal esophageal/forestomach ESCC. Tissue microarrays of esophageal neoplasms and ESCC as well as extracted tumor samples were stained for periostin. Results: We generated a ${ }^{64} \mathrm{Cu}-\mathrm{DOTA}-\mathrm{anti}-$ periostin- $F(a b)_{2}$ with a dissociation constant of $29.2 \pm 3.0 \mathrm{nM}$. PET/CT images and biodistribution studies showed significantly higher tracer uptake in TE-11 than TT tumors (maximum standardized uptake value, $24 \mathrm{~h}$ : $0.67 \pm 0.09$ vs. $0.36 \pm 0.03, P<0.0005$; percentage injected dose per gram, 24 h: $3.24 \pm 0.65$ vs. $1.63 \pm 0.49, P<0.0001$ ). In genetically engineered mouse models, ESCC high periostin tracer uptake anatomically correlated with the ${ }^{18} \mathrm{~F}-\mathrm{FDG}$ uptake at the gastroesophageal junction. All of the ESCC cores and $96.2 \%$ of adenocarcinoma stained positive for periostin, with most stained strongly (67.3\% and $69.3 \%$, respectively). Conclusion: We demonstrated that specific imaging of extracellular matrix periostin in ESCC is feasible using a targeted PET tracer. Detection of periostin in the tumor microenvironment may help with early detection, postsurgical follow-up, and in situ characterization of primary and metastatic lesions.

Key Words: periostin; immuno-PET imaging; extracellular matrix; tumor microenvironment; esophageal cancer

J Nucl Med 2015; 56:1246-1251

DOI: 10.2967/jnumed.115.156216

Received Feb. 23, 2015; revision accepted May 28, 2015.

For correspondence or reprints contact: Umar Mahmood, Athinoula A. Martinos Center for Biomedical Imaging, Department of Radiology,

Massachusetts General Hospital, Boston, MA 02129.

E-mail: umahmood@mgh.harvard.edu

${ }^{*}$ Contributed equally to this work.

Published online Jun. 11, 2015.

COPYRIGHT (C 2015 by the Society of Nuclear Medicine and Molecular Imaging, Inc.
$\mathbf{P}$ highly expressed during embryonic development but has low basal expression in adult tissue (1-3). It is only reexpressed and upregulated again in cancers such as head and neck squamous cell carcinoma, thymoma, esophageal, breast, ovarian, and non-small cell lung cancer (4-11). It plays a key role in cell signaling, cell-to-cell adhesion, and motility within the tumor microenvironment (12). It interacts with multiple cell surface receptors, most notably integrins, and signals via multiple pathways to promote cancer cell survival, epithelialmesenchymal transition, invasion, angiogenesis, and metastasis (13). Periostin is highly upregulated in esophageal squamous cell carcinoma (ESCC), and elevated levels of periostin can be detected in the sera of many ESCC patients. Recent studies demonstrated that periostin is the most upregulated ECM protein in tumor invasion gene signature for esophageal cancer and operates as an important mediator of invasion within the tumor microenvironment (14).

Despite increasing knowledge of the ECM changes in different neoplastic diseases, these elements have not been previously explored as imaging targets for evaluation of tumor growth and invasion. Given the key role of periostin in facilitating tumor cell invasion through ECM remodeling, specific periostin-targeting probes could constitute a valuable new class of molecular imaging agents for characterizing the invasive potential of neoplastic lesions. Moreover, the advent of periostin-targeted therapies for cancer treatment highlights the potential of periostin-targeted PET probes to improve patient care through noninvasive temporal assessment of periostin expression $(15,16)$.

Building on this foundation, we proposed that PET imaging of periostin in the ECM could be used for tumor characterization. In this study, we aimed to develop and characterize a novel PET tracer that specifically targets periostin and evaluate the in vivo potential of the developed probe for assessment of ECM in preclinical cancer models.

\section{MATERIALS AND METHODS}

\section{Mouse Models of Human Esophageal Cancer}

The Institutional Animal Care and Use Committee at the Massachusetts General Hospital approved all animal studies. Mice were housed under a 12-h light/dark cycle and fed ad libitum.

Two human ESCC cell lines, TE-11 (with high periostin expression) and TT (with minimal periostin expression), were cultivated in 
Dulbecco modified Eagle medium (Fisher Scientific) supplemented by $10 \%$ fetal calf serum (Atlanta Bioscience) and $1 \%$ penicillin/streptomycin (Invitrogen) and grown in 5\% $\mathrm{CO} 2$ conditions as described previously (14). The cell lines were subcutaneously implanted in $n u / n u$ mice $(n=5$ for each cell line). TE-11 cells with high expression and TT cells with minimal expression of periostin were used to generate the positive and control tumor models.

We additionally used a genetically engineered mouse model (GEMM) of ESCC by conditionally deleting the cell adhesion molecule p120ctn (L2-Cre;p120ctn LoxP/LoxP) as previously described $(13,17,18)$. Mice were genotyped for the LoxP and Cre allele as described previously $(13,18)$. This mouse model demonstrates enhanced periostin concentration in serum and high local expression of periostin in the distal esophagus and forestomach with progression of ESCC.

\section{Development and Characterization of PET Probe and Radiolabeling Procedures}

We developed a periostin imaging PET probe by enzymatic fragmentation of a monoclonal antibody (SAB4200197; Sigma-Aldrich Inc.) to $\mathrm{F}\left(\mathrm{ab}^{\prime}\right)_{2}$ fragments. Briefly, $\mathrm{F}\left(\mathrm{ab}^{\prime}\right)_{2}$ fragments were prepared by specific enzymatic digestion using a FragIT MicroSpin column (Genovis) and purified by an immobilized NAb Protein A spin column (ThermoScientific). Antiperiostin- $\mathrm{F}\left(\mathrm{ab}^{\prime}\right)_{2}$ was conjugated with the bifunctional 2-(4isothiocyanatobenzyl)-1,4,7,10-tetraazacyclodo-decane-1,4,7,10-tetraacetic acid (p-SCN-Bn-DOTA; Macrocyclics, Inc.) chelate in anhydrous dimethyl sulfoxide using a 10-fold molar excess of chelate to antiperiostin $\mathrm{F}\left(\mathrm{ab}^{\prime}\right)_{2}$. DOTA-antiperiostin- $\mathrm{F}\left(\mathrm{ab}^{\prime}\right)_{2}$ was purified from excess DOTA using an Amicon Ultracel 30K device. The DOTA substitution level of the $\mathrm{F}\left(\mathrm{ab}^{\prime}\right)_{2}$ fragments was calculated by labeling a sample of unpurified conjugate with ${ }^{67} \mathrm{Ga}$ and then measuring the relative proportion of ${ }^{67} \mathrm{Ga}$-DOTA-antiperiostin-F $\left(\mathrm{ab}^{\prime}\right)_{2}$ versus ${ }^{67} \mathrm{Ga}$-DOTA using instant thin-layer chromatography silica gel (19). Radiolabeling with ${ }^{64} \mathrm{Cu}$ (University of Wisconsin) was performed by incubating $50-100 \mu \mathrm{g}$ of DOTA-antiperiostin- $\mathrm{F}\left(\mathrm{ab}^{\prime}\right)_{2}$ in $0.25 \mathrm{M}$ ammonium acetate buffer (pH 6.0) with ${ }^{64} \mathrm{CuCl}_{2}$ (37-74 MBq of ${ }^{64} \mathrm{Cu}$ per $25 \mathrm{mg}$ of antibody). The labeled conjugate was purified using an Amicon Ultracel $30 \mathrm{~K}$ device as described before (19).

\section{Competitive Binding Studies}

The dissociation constant of ${ }^{64} \mathrm{Cu}-\mathrm{DOTA}$-antiperiostin- $\mathrm{F}\left(\mathrm{ab}^{\prime}\right)_{2}$ was determined by direct (saturation) radioligand binding assay in triplicate. Briefly, recombinant human periostin with a C-terminal 6-his tag (R \& D systems) was fixed to HisLink Protein Purification Resin (Promega). HisLink Protein Purification Resin $(100 \mu \mathrm{L})$ containing $7 \mu \mathrm{g}$ of recombinant human periostin was added to sealed spin columns. Increasing concentrations $(0-100 \mathrm{nmol} / \mathrm{L})$ of ${ }^{64} \mathrm{Cu}$-DOTAantiperiostin- $\mathrm{F}\left(\mathrm{ab}^{\prime}\right)_{2}$ were added to each spin column and incubated at $4^{\circ} \mathrm{C}$ for $3 \mathrm{~h}$ on a shaker. Unbound radioactivity was removed by spinning the spin column at $14,000 \mathrm{rpm}$ for $5 \mathrm{~min}$. The column was then washed and spun 6 times with $4^{\circ} \mathrm{C}$ HisLink Binding/Wash Buffer (Promega). The total bound radioactivity was measured using a $\gamma$ counter (Wizard 2480; Perkin Elmer). The assay was repeated with HisLink Protein Purification Resin not containing periostin to measure nonspecific binding. Specific binding was calculated by subtracting nonspecific binding from total bound radioactivity and plotted against the concentration of ${ }^{64} \mathrm{Cu}$-DOTA-antiperiostin- $\mathrm{F}\left(\mathrm{ab}^{\prime}\right)_{2}$. The resulting curve was fitted by nonlinear regression to a 1-site receptor-binding model, and the dissociation constant $\left(\mathrm{K}_{\mathrm{d}}\right)$ was calculated.

\section{PET/CT Imaging}

We evaluated the developed PET probe ability to bind periostin in subcutaneous ESCC xenografts and orthotopic spontaneous tumors in the esophagus of GEMM mice with p120ctn conditional knock-out. PET/CT scanning was performed at 6,12 , and $24 \mathrm{~h}$ after intravenous injection of
$8.99 \pm 1.81 \mathrm{MBq}(243 \pm 49 \mu \mathrm{Ci}$, mean $\pm \mathrm{SD})$ of ${ }^{64} \mathrm{Cu}-\mathrm{DOTA}$-antiperiostin- $\mathrm{F}\left(\mathrm{ab}^{\prime}\right)_{2}$ via the lateral tail vein using a 30 -gauge catheter in mice with xenografts and GEMM mice. The imaging time points were selected based on our previous experience with $\mathrm{F}\left(\mathrm{ab}^{\prime}\right)_{2}$ probes. The 6-h time point was the earliest time point imaged, to allow the background from the blood pool to drop enough to permit xenograft imaging. ${ }^{18} \mathrm{~F}$ FDG PET/CT was performed $1 \mathrm{~h}$ after injection of $8.36 \pm 1.33 \mathrm{MBq}$ $(226 \pm 36 \mu \mathrm{Ci}$, mean $\pm \mathrm{SD})$ of ${ }^{18} \mathrm{~F}-\mathrm{FDG}$ via the tail vein in GEMM mice. Mice were fasted for at least $4 \mathrm{~h}$ before ${ }^{18} \mathrm{~F}-\mathrm{FDG}$ injection. $\mathrm{PET} / \mathrm{CT}$ data were acquired and reconstructed as described before $(19,20)$. Three-dimensional regions of interest (ROIs) were manually drawn around tumors based on coregistered CT scans acquired immediately after PET imaging. Maximum standardized uptake value (SUV) and mean SUV ( $\mathrm{SUV}_{\text {mean }}$ ) were calculated within the ROI. ${ }^{64} \mathrm{Cu}-$ DOTA-antiperiostin- $\mathrm{F}\left(\mathrm{ab}^{\prime}\right)_{2} \mathrm{SUV}_{\text {mean }}$ was also normalized to bloodpool activity at the time of scanning from a 3-dimensional spheric 3-mm ROI drawn within the heart and was expressed as target-tobackground ratio (TBR).

\section{In Vivo Biodistribution}

Biodistribution studies were conducted $24 \mathrm{~h}$ after tracer injection $(n=4)$. Briefly, approximately $1.85 \mathrm{MBq}(50 \mu \mathrm{Ci})$ of ${ }^{64} \mathrm{Cu}$-DOTA-antiperiostin$\mathrm{F}\left(\mathrm{ab}^{\prime}\right)_{2}$ were injected via the tail vein to mice bearing TE-11 and TT xenografts. Animals ( $n=4$ for each condition) were sacrificed at $24 \mathrm{~h}$ after injection, organs of interest were harvested and weighed, and the corresponding radioactivity was measured on a $\gamma$ counter. After correcting for background and decay, the percentage injected dose per gram (\% ID/g) was calculated.

\section{Histopathologic Analysis}

Mice were sacrificed by $\mathrm{CO} 2$ suffocation. Tumors were extracted and washed using normal saline solution. The samples were then instantly frozen in liquid nitrogen and sectioned. All tissues were stained with hematoxylin and eosin for the histologic evaluation. Light microscopy images were acquired with an Olympus IX51 microscope.

Immunohistochemical analysis was performed on xenografts and GEMM tissue samples as described previously $(14,21)$. Briefly, unstained $5-\mu \mathrm{m}$ sections were fixed by standard techniques before antigen retrieval in ethylenediaminetetraacetic acid buffer. The samples were then incubated by the 1:50 dilution of antiperiostin rabbit polyclonal IgG (ab14041; Abcam) overnight at $4^{\circ} \mathrm{C}$. The sections were washed in Tris-buffered saline and polysorbate 20 mixture and incubated with biotinylated goat antirabbit IgG (Abcam) for $1 \mathrm{~h}$. The staining was developed by incubation in liquid 3,3'-diaminobenzidine (Dako) for $1 \mathrm{~min}$. Slides were washed in distillated water and counterstained with hematoxylin (Richard-Allan Scientific) and dehydrated before mounting. Two esophageal cancer tissue arrays (ES2081 and ES2001; US Biomax) were stained for periostin expression with slight modification of the technique described above. The scoring for periostin expression was done as previously described (13).

\section{Statistical Analysis}

Data are expressed as mean \pm SD unless noted otherwise. Statistical significance was determined with an unpaired, 2-tailed Student $t$ test and $95 \%$ confidence level, and $P$ values less than 0.05 were considered significant. All data were analyzed and plotted using Prism software (version 6.0; GraphPad Software).

\section{RESULTS}

Periostin Expression in Tissue Array of Esophageal Cancer

Immunohistochemical analysis of 2 tissue microarrays showed that $100 \%$ of ESCC cores and $96.2 \%$ of adenocarcinoma stained positive for periostin, with most stained strongly for periostin in both tumor types $(67.3 \%$ and $69.3 \%$, respectively). Although $70 \%$ 


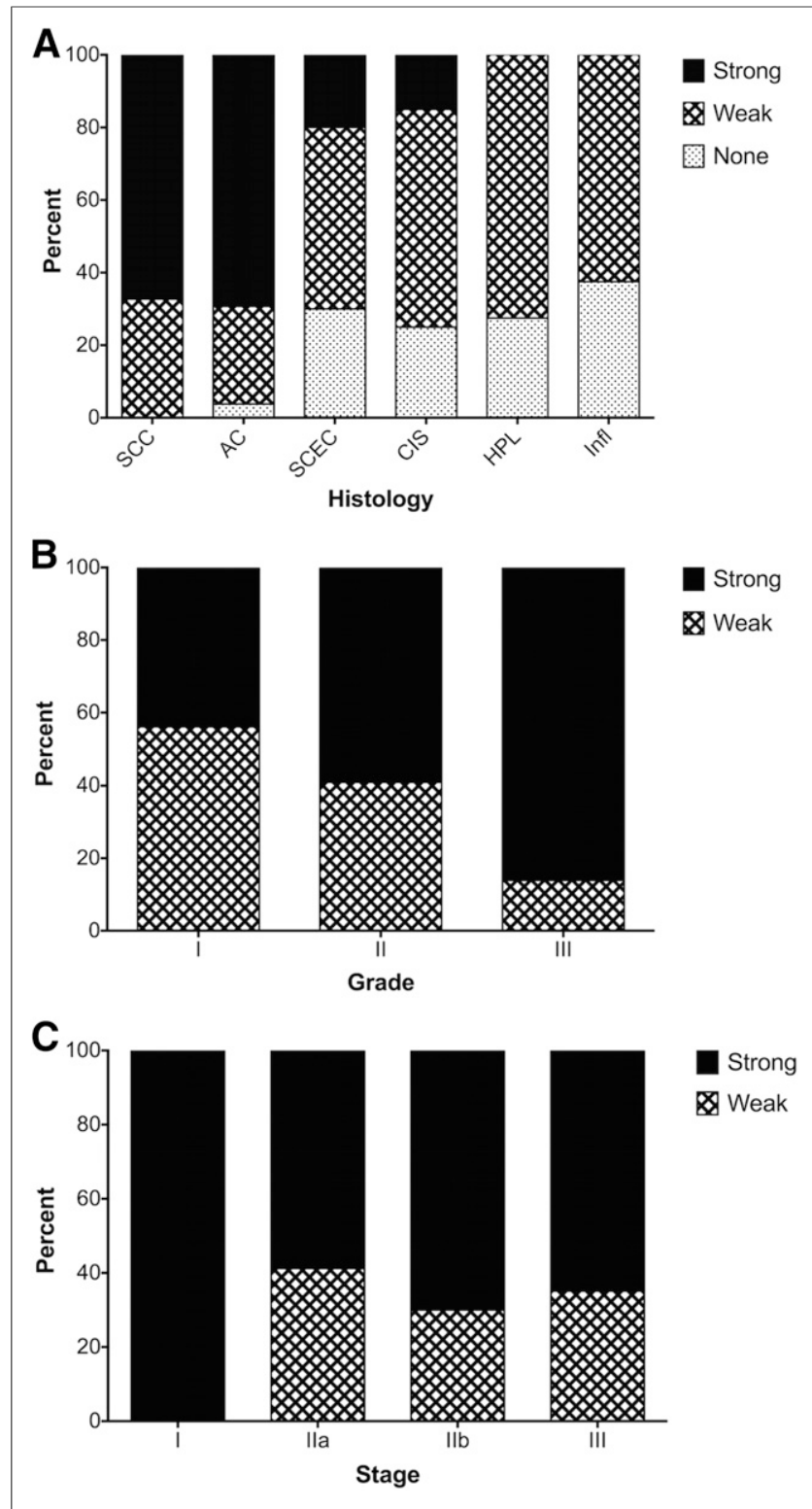

FIGURE 1. Immunohistochemical staining of esophageal tissue arrays for periostin. (A) Almost all of the tissue samples of SSC and adenocarcinoma stained positive for periostin, with most stained strongly for periostin. Only $15 \%$ of carcinoma in situ stained strongly for periostin, and none of the hyperplasia or inflammation samples stained strongly for periostin. (B) Among primary SCC tissue samples, periostin staining significantly changed with tumor grade, with higher-grade tumors exhibiting significantly stronger periostin staining. (C) There was no significant change of periostin staining with changes in tumor stage. $\mathrm{AC}=$ adenocarcinoma; $\mathrm{CIS}=$ carcinoma in situ; HPL = hyperplasia; Infl $=$ inflammation; SCEC $=$ small cell esophageal cancer .

of cores with small cell esophageal cancer showed positive periostin expression, only $20 \%$ of tissue samples expressed this ECM protein at a high level. A comparison of the neoplastic changes pattern in 3 levels of chronic inflammation, hyperplasia, and carcinoma in situ revealed that only $15 \%$ of carcinoma in situ stained strongly for periostin and none of the hyperplasia or inflammation samples stained strongly for periostin (Fig. 1A). Among the primary SCC tissue samples, scoring analysis showed a trend toward increased levels of periostin expression; higher-grade tumors exhibited significantly stronger periostin staining, showing $43.9 \%$ in grade $1,59 \%$ in grade 2 , and $86.1 \%$ in grade $3(P<0.0006)$ (Fig. 1B). There was no significant change in periostin staining with change in the stage of SCC tumors $(P>0.379)$ (Fig. 1C).

\section{Radiotracer Preparation and Characterization}

We efficiently generated $\mathrm{F}\left(\mathrm{ab}^{\prime}\right)_{2}$ using the described enzymatic digestion method and recovered $0.66 \mathrm{mg} \mathrm{F}\left(\mathrm{ab}^{\prime}\right)_{2}$ from each milligram of antiperiostin whole antibody ( $\sim 66 \%$ yield). The sitespecific enzymatic digestion and protein $\mathrm{A}$ affinity purification resulted in greater than $98 \%$ purity of the $\mathrm{F}\left(\mathrm{ab}^{\prime}\right)_{2}$ fragments shown by both size-exclusion fast protein liquid chromatography and sodium dodecyl sulfate polyacrylamide gel electrophoresis. Reaction of $\mathrm{F}\left(\mathrm{ab}^{\prime}\right)_{2}$ with a 10 -fold molar excess of p-SCN-Bn-DOTA resulted in substitution of approximately 1.05 DOTA chelate per $\mathrm{F}\left(\mathrm{ab}^{\prime}\right)_{2}$ molecule. The labeling efficiency for ${ }^{64} \mathrm{Cu}$-DOTA-antiperiostin$\mathrm{F}\left(\mathrm{ab}^{\prime}\right)_{2}$ was $70 \% \pm 3.5 \%$ and with $99 \%$ or greater radiochemical purity. The specific activity of ${ }^{64} \mathrm{Cu}$-DOTA-antiperiostin- $\mathrm{F}\left(\mathrm{ab}^{\prime}\right)_{2}$ was $666 \pm 211 \mathrm{kBq} / \mu \mathrm{g}$.

Direct (saturation) radioligand binding assays showed that ${ }^{64} \mathrm{Cu}$-DOTA-antiperiostin- $\mathrm{F}\left(\mathrm{ab}^{\prime}\right)_{2}$ bound specifically to human recombinant periostin fixed to HisLink Protein Purification Resin. The $\mathrm{K}_{\mathrm{d}}$ for ${ }^{64} \mathrm{Cu}$-DOTA-antiperiostin- $\mathrm{F}\left(\mathrm{ab}^{\prime}\right)_{2}$ was $29.2 \pm 3.0 \mathrm{nM}$ (Fig. 2).

\section{In Vivo PET Imaging}

${ }^{64} \mathrm{Cu}$-DOTA-antiperiostin- $\mathrm{F}\left(\mathrm{ab}^{\prime}\right)_{2}$ PET/CT of the subcutaneous xenografts showed significantly higher tracer uptake in TE-11 tumors than in TT tumors at 6-, 12-, and 24-h time points (Table 1; Figs. 3A and 3C). In both TE-11 and TT xenografts, the detected activity was higher at $6 \mathrm{~h}$ than at $12 \mathrm{~h}$. We believe the higher maximum SUV and $\mathrm{SUV}_{\text {mean }}$ at $6 \mathrm{~h}$, compared with $12 \mathrm{~h}$, can be explained by significantly higher activity in the blood pool in the earlier hours of ${ }^{64} \mathrm{Cu}$-DOTA-antiperiostin- $\mathrm{F}\left(\mathrm{ab}^{\prime}\right)_{2}$ injection (Table 1; Fig. 3B). As expected, the blood pool clears from $\mathrm{F}\left(\mathrm{ab}^{\prime}\right)_{2}$ over time. There was no difference in the blood-pool activity between mice bearing TE-11 and those bearing TT xenografts at any time points (Table 1; Fig. 3B). The TBR monotonously increased in both TE-11 and TT over time; however, the TBR increased at

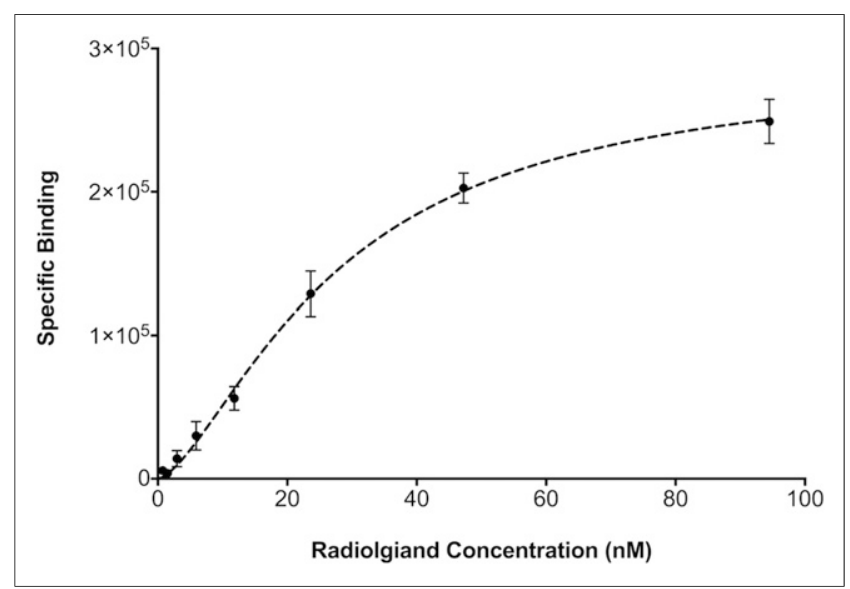

FIGURE 2. Direct (saturation) radioligand binding assays showed that ${ }^{64} \mathrm{Cu}$-DOTA-antiperiostin- $\mathrm{F}\left(\mathrm{ab} \mathrm{b}_{2}\right)_{2}$ bound specifically to human recombinant periostin fixed to HisLink Protein Purification Resin. The $K_{d}$ value for ${ }^{64} \mathrm{Cu}$-DOTA-antiperiostin- $\mathrm{F}\left(\mathrm{ab}^{\prime}\right)_{2}$ was $29.2 \pm 3.0 \mathrm{nM}$. 
TABLE 1

The PET Quantitative Values in TE-11 and TT Xenografts

\begin{tabular}{|c|c|c|c|c|}
\hline Region of interest & Time point & TE-11 & $\pi$ & $P$ \\
\hline Tumor & 6 & $0.490 \pm 0.063$ & $0.278 \pm 0.088$ & $0.0082^{*}$ \\
\hline \multirow[t]{2}{*}{ Maximum SUV } & 12 & $0.364 \pm 0.052$ & $0.210 \pm 0.039$ & $0.0031^{*}$ \\
\hline & 24 & $0.665 \pm 0.093$ & $0.356 \pm 0.033$ & $0.0008^{*}$ \\
\hline \multirow[t]{3}{*}{ Tumor (SUV $\left.V_{\text {mean }}\right)$} & 6 & $0.350 \pm 0.046$ & $0.214 \pm 0.043$ & $0.005^{\star}$ \\
\hline & 12 & $0.271 \pm 0.036$ & $0.154 \pm 0.028$ & $0.002^{*}$ \\
\hline & 24 & $0.501 \pm 0.069$ & $0.251 \pm 0.033$ & $0.0006^{*}$ \\
\hline \multirow[t]{3}{*}{ Blood (SUV $\left.V_{\text {mean }}\right)$} & 6 & $0.488 \pm 0.064$ & $0.463 \pm 0.060$ & 0.589 \\
\hline & 12 & $0.258 \pm 0.034$ & $0.249 \pm 0.033$ & 0.717 \\
\hline & 24 & $0.250 \pm 0.033$ & $0.241 \pm 0.031$ & 0.704 \\
\hline \multirow[t]{3}{*}{ Tumor to background } & 6 & $0.717 \pm 0.095$ & $0.463 \pm 0.093$ & $0.0087^{*}$ \\
\hline & 12 & $1.047 \pm 0.140$ & $0.617 \pm 0.111$ & $0.0009^{*}$ \\
\hline & 24 & $2.000 \pm 0.263$ & $1.041 \pm 0.136$ & $0.0006^{*}$ \\
\hline
\end{tabular}

*Statistically significant; provided values represent mean \pm SD.

a steeper slope in TE-11 xenografts than TT tumors (Table 1; Fig. 3D). The TBR in TE-11 was significantly higher than that in TT xenografts at every time point $(P<0.0001)$. We found that the $\mathrm{SUV}_{\text {mean }}$ of TT xenografts was below or equal to background through all the time points (Table 1; Figs. 3B and 3C). Representative ${ }^{64} \mathrm{Cu}$-DOTA-antiperiostin- $\mathrm{F}\left(\mathrm{ab}^{\prime}\right)_{2}$ PET/CT images of TE-11 tumors and TT xenografts are shown in Figures 4A and 4B, respectively.

PET/CT imaging with ${ }^{64} \mathrm{Cu}$-DOTA-antiperiostin- $\mathrm{F}\left(\mathrm{ab}^{\prime}\right)_{2}$ in the GEMM of orthotopic ESCC showed high periostin tracer uptake $\left(\mathrm{SUV}_{\text {mean }}, 0.54 \pm 0.03\right)$ anatomically correlating with the site of enhanced ${ }^{18}$ F-FDG uptake $\left(\mathrm{SUV}_{\text {mean }}, 0.91 \pm 0.03\right)$ (Fig. 5). We further confirmed that the presence of ESCC at the gastroesophageal junction in the mice demonstrated enhanced ${ }^{64} \mathrm{Cu}$-DOTAantiperiostin-F $\left(\mathrm{ab}^{\prime}\right)_{2}$ and ${ }^{18} \mathrm{~F}-\mathrm{FDG}$ uptake using histopathology (Supplemental Fig. 2; supplemental materials are available at http://jnm.snmjournals.org).

\section{Biodistribution}

The in vivo pharmacokinetic characteristics of ${ }^{64} \mathrm{Cu}$-DOTAantiperiostin- $\mathrm{F}\left(\mathrm{ab}^{\prime}\right)_{2}$ were investigated by performing biodistribution studies in mice bearing TE-11 (periostin-positive) and TT (minimal periostin expression) subcutaneous xenografts $24 \mathrm{~h}$ after tracer administration. The results of these studies are summarized in Figure 6. Analysis of tumor-associated activity revealed a significant $1.98 \pm 0.23$-fold increase in accumulation of ${ }^{64} \mathrm{Cu}$ DOTA-antiperiostin- $\mathrm{F}\left(\mathrm{ab}^{\prime}\right)_{2}$ in the TE-11, compared with the TT, xenografts $(3.24 \pm 0.65$ and $1.63 \pm 0.49 \% \mathrm{ID} / \mathrm{g}$, respectively; $P<0$. 0281). We observed that both TE-11 and TT have higher uptake, compared with the esophagus $(1.05 \pm 0.19 \% \mathrm{ID} / \mathrm{g})$ and small bowel $(0.93 \pm 0.20 \% \mathrm{ID} / \mathrm{g})$. However, the difference between the uptake by TT xenografts and esophagus or small bowel uptake was not statistically significant $(P>0.12$ and $>0.06$, respectively). Other organs retained similar amounts of the tracer in animals bearing both TE-11 and TT xenografts (Fig. 6). In animals bearing TT xenografts, comparison of tumor-associated activity to that remaining in circulation did not demonstrate a significant difference $(1.63 \pm 0.49$ and $1.55 \pm 0.29 \% \mathrm{ID} / \mathrm{g}$, respectively;
$P=0.82)$. As expected, a relatively high amount of tracer retention was measured in the kidneys $(6.91 \pm 2.69 \% \mathrm{ID} / \mathrm{g}$ in TE-11-bearing mice and $6.52 \pm 1.78 \% \mathrm{ID} / \mathrm{g}$ in TT-bearing mice) and liver (4.35 \pm $1.24 \% \mathrm{ID} / \mathrm{g}$ in TE-11-bearing mice and $4.10 \pm 1.03 \% \mathrm{ID} / \mathrm{g}$ in TTbearing mice), the major clearance organs for $\mathrm{F}\left(\mathrm{ab}^{\prime}\right)_{2}$ radiotracers. In animals bearing TE-11 or TT tumors, activity detected in the lung and spleen-1.27 $\pm 0.40 \% \mathrm{ID} / \mathrm{g}$ in TE-11 and $1.36 \pm 0.31$ $\% \mathrm{ID} / \mathrm{g}$ in TT and $1.12 \pm 0.35 \% \mathrm{ID} / \mathrm{g}$ in TE-11 and $1.31 \pm 0.37$ $\% \mathrm{ID} / \mathrm{g}$ in $\mathrm{TT}$ - was similar to that present in circulation, $1.60 \pm$ $0.37 \% \mathrm{ID} / \mathrm{g}$ in TE-11 and $1.55 \pm 0.129 \% \mathrm{ID} / \mathrm{g}$ in TT.

\section{Periostin Expression in Xenografts and GEMM}

Immunohistochemical staining for periostin revealed weak staining in control (TT) xenografts (Supplemental Figs. 1A and

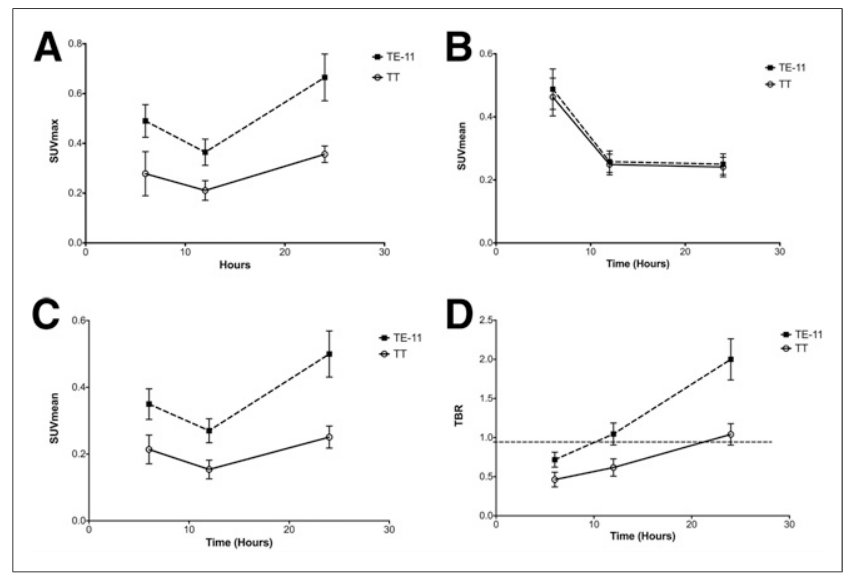

FIGURE 3. Quantitative PET imaging of xenografts TE-11 and TT at different time points after intravenous injection of probe. (A-C) Bloodpool activity decreases over time, and uptake in tumors increases over $24 \mathrm{~h}$ after injection of ${ }^{64} \mathrm{Cu}-\mathrm{DOTA}$-antiperiostin- $\mathrm{F}\left(\mathrm{ab}^{\prime}\right)_{2}$ probe. (D) TBR linearly increases in both xenografts but at greater slope in TE-11 xenografts, compared with TT tumors. TE- 11 TBR reached approximately 2 at $24 \mathrm{~h}$ after injection. SUV $\max =$ maximum standardized uptake value. 


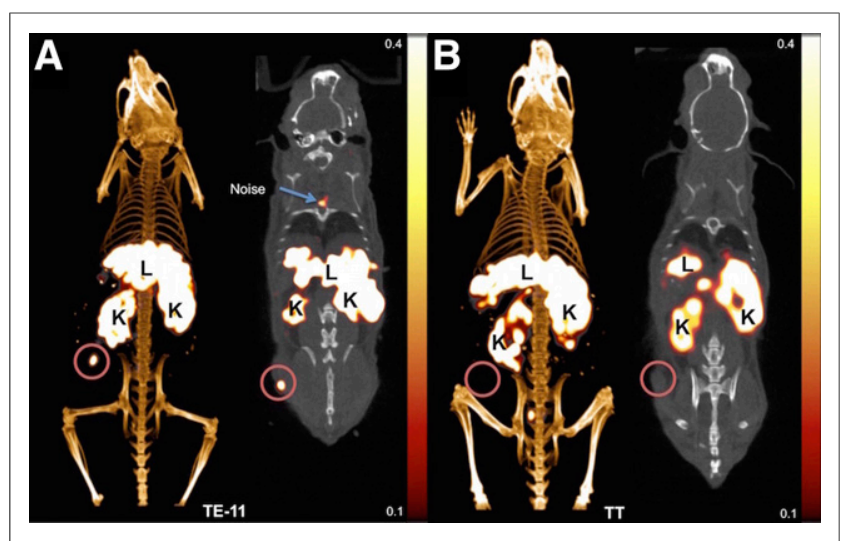

FIGURE 4. Representative PET/CT images using ${ }^{64} \mathrm{Cu}$-DOTA-antiperiostin- $\left.\mathrm{F}(\mathrm{ab})_{2}\right)_{2}$ show high uptake of probe in subcutaneously implanted human esophageal squamous cell TE-11 tumors (A) and minimal uptake in $T$ tumors (B). $K=$ kidney; $L=$ liver.

1B), whereas strong staining was observed in both TE-11 xenografts (Supplemental Figs. 1C and 1D) and spontaneous orthotopic ESCC tumors from GEMM with conditional p120ctn knock-out (L2-Cre; p120ctn ${ }^{\text {LoxP/LoxP) }}$ (Supplemental Fig. 2).

\section{DISCUSSION}

In this study, we developed an antiperiostin ${ }^{64} \mathrm{Cu}-\mathrm{DOTA}-\mathrm{F}\left(\mathrm{ab}^{\prime}\right)_{2}$ imaging PET probe and tested the probe in murine models of ESCC. We showed that the probe has a relatively high affinity for periostin $\left(\mathrm{K}_{\mathrm{d}}=29 \mathrm{nM}\right)$. The probe was tested in 2 independent ESCC xenograft models (TE-11 and TT). We observed high radiotracer uptake in the TE-11 xenografts expressing periostin, compared with low tracer uptake in TT xenografts, which minimally express periostin (Fig. 4), highlighting that ${ }^{64} \mathrm{Cu}$-DOTA-antiperiostin- $\mathrm{F}\left(\mathrm{ab}^{\prime}\right)_{2}$ uptake parallels the expression of periostin in tumor tissue. There was similar distribution of radiotracer in normal organs of the mice bearing TE-11 or TT xenografts. We observed high tumor tracer uptake in a GEMM of ESCC that specifically expresses high levels of periostin within the spontaneous esophageal tumors. The model recapitulates the temporal progression of human ESCC by conditional deletion of p120 catenin (p120ctn) in the foregut. We observed high ${ }^{64} \mathrm{Cu}$-DOTA-antiperiostin- $\mathrm{F}\left(\mathrm{ab}^{\prime}\right)_{2}$ accumulation in the gastroesophageal junction tumor in these mice in the same location in which we saw enhanced ${ }^{18} \mathrm{~F}-\mathrm{FDG}$ uptake in the esophagus. The presence of periostin-expressing ESCC was confirmed by histopathology.

Tissue array staining for periostin showed that more than two thirds of human esophageal carcinomas strongly express periostin whereas only $10 \%-20 \%$ of benign esophageal lesions express periostin. The positive staining of the small percentage of benign esophageal lesions may be related to the presence of early molecular changes, which could potentially precede dysplastic changes in the sampled tissue and which is not captured morphologically in the tissue core. The array data demonstrate that the expression of periostin increases in higher-grade tumors. This finding is consistent with prior reports that showed that POSTN (periostin gene) is the most upregulated gene in the invasion profile of the ESCC tumors (14). The development of the periostin imaging probe could help to identify tumors with more invasive biologic behavior that could thus potentially warrant more aggressive treatment.
Our results with the developed PET agent extend an earlier study in which we used a polyclonal antiperiostin antibody-Cy5.5 conjugate to optically image TE-11 and TT xenografts as well as spontaneous esophageal tumors with near-infrared fluorescence endoscopy. We showed strong fluorescence in TE-11, compared with low-fluorescence signal in TT xenografts, and significant reduction in the fluorescence of TE-11 xenografts after incubation with excess unlabeled antibody, demonstrating in vivo specificity. Upper gastrointestinal multispectral endoscopy in the spontaneous mouse models showed high-fluorescence signal in severe esophageal dysplasia, compared with low signal in mild dysplasia and no signal in control mice (14). In the current study, we chose a monoclonal instead of a polyclonal antibody, to improve specificity and the uniformity of the imaging probe. Moreover, because periostin is a soluble molecule that is slowly eliminated from the ECM, the prolonged circulation time of whole antibody probe in the earlier study was less desirable, prompting us to use $\mathrm{F}\left(\mathrm{ab}^{\prime}\right)_{2}$ fragments instead of the intact antibody, hastening tracer clearance from background tissue and blood pool and allowing imaging at somewhat earlier time points.

Despite increasing knowledge of the ECM changes in neoplastic disease, these elements have not been extensively explored as imaging targets. The solubility of ECM proteins and their abundance in the body pose a challenge for in vivo imaging. However, the local binding of periostin to other ECM proteins and slower turnover of this protein in the ECM prevents periostin from rapid dispersion in the body after secretion from tumor cells. Also, the lack of expression of periostin after the fetal period results in high local concentration of the molecule in tumors relative to background. Given the key role of periostin in facilitating tumor cell invasion through ECM remodeling, periostin is also an attractive therapeutic target. Novel site-specific antiperiostin $\mathrm{mAb}$ such as OC-20 have shown great promise in inhibition of tumor angiogenesis and growth $(15,16,22)$ and are now under investigation in translational and early clinical studies for treatment of epithelial cancers. Thus, specific periostin-targeting PET probes could constitute valuable molecular imaging agents for characterizing the invasive potential of neoplastic lesions and to potentially help guide targeted treatment based on individual overexpression levels.

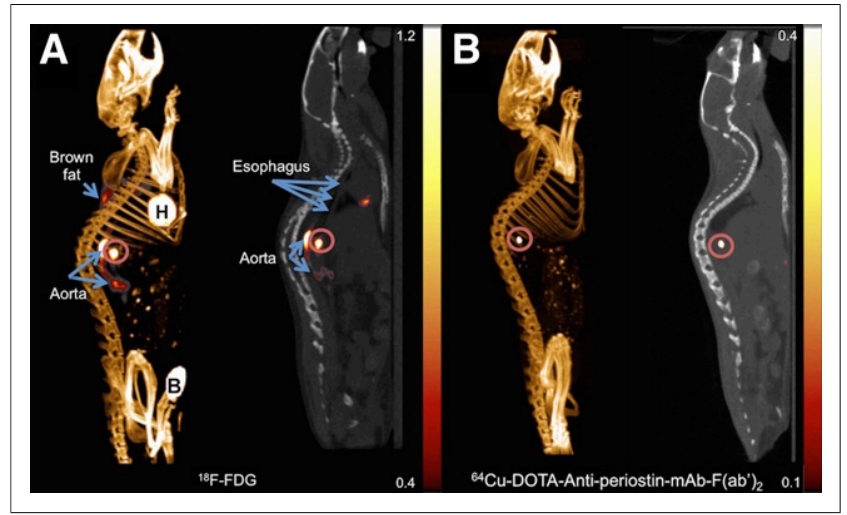

FIGURE 5. Representative ${ }^{18} \mathrm{~F}-\mathrm{FDG}$ PET/CT scan of L2Cre-p120loxp/loxp mouse shows tumor in gastroesophageal junction ( $A$ and $B$ ), whereas $\mathrm{PET} / \mathrm{CT}$ imaging with ${ }^{64} \mathrm{Cu}$-DOTA-antiperiostin- $\mathrm{F}\left(\mathrm{ab}^{\prime}\right)_{2}$ shows specific uptake in same location of high uptake with no increased uptake in adjacent organs such as aorta $(C$ and $D)$. $B=$ bladder; $H=$ heart; $\mathrm{K}=$ kidney. 


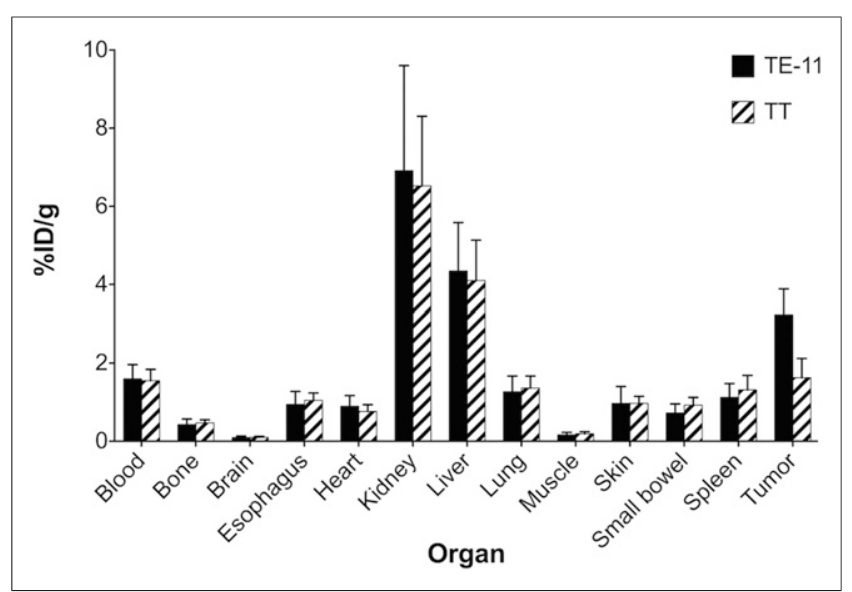

FIGURE 6. Biodistribution studies $24 \mathrm{~h}$ after injection confirmed our results, with $\mathrm{PET} / \mathrm{CT}$ imaging demonstrating significantly higher accumulation of ${ }^{64} \mathrm{Cu}$-DOTA-antiperiostin- $\mathrm{F}\left(\mathrm{ab}^{\prime}\right)_{2}$ in TE-11 tumors and compared with negative control, TT tumors. PET probe is cleared from other organs and excreted through kidney and liver.

There are several limitations to this study. First, because periostin is a soluble protein, constantly secreted by tumor cells to the ECM, in vivo blocking studies pose a challenge. On the basis of our experience with the fluorescently labeled antiperiostin polyclonal antibody, high concentrations of circulating antiperiostin antibody would be required to continuously block the binding sites of the secreted periostin. Given the lack of commercial availability of large quantities of the antibody, it was not feasible to perform an in vivo blocking study with the monoclonal antibody. However, we tested the imaging agent in negative control xenografts derived from a cell line with minimal periostin expression and showed the lack of binding in these xenografts. Second, because of the biodistribution of antibodybased probes there is an inherently high uptake in the liver, which limits the value of this probe in evaluation of hepatic metastases.

\section{CONCLUSION}

In this study, we developed and applied a periostin-targeting PET probe for the first time, to our knowledge, in the preclinical setting for noninvasive assessment of the ECM. Our results showed that in vivo imaging of ECM periostin is feasible using a targeted PET tracer. This probe may be used to characterize the invasive potential of neoplastic lesions, enabling the evaluation and quantitation of this important hallmark of cancer as a potential determinant of prognosis and target-guided treatment strategies. In the future, this probe could be used to improve the management of patients by optimizing individualized targeted therapy through noninvasive temporal assessment of periostin expression heterogeneity across all metastatic sites, dose adjustment of targeted therapies, postsurgical follow-up, and assessment of the effectiveness of novel targeted antimetastatic therapies.

\section{DISCLOSURE}

The costs of publication of this article were defrayed in part by the payment of page charges. Therefore, and solely to indicate this fact, this article is hereby marked "advertisement" in accordance with 18 USC section 1734. This research was supported in part by National Institutes of Health grants U01CA084301 and P50CA127003. No other potential conflict of interest relevant to this article was reported.

\section{REFERENCES}

1. Butcher JT, Norris RA, Hoffman S, Mjaatvedt CH, Markwald RR. Periostin promotes atrioventricular mesenchyme matrix invasion and remodeling mediated by integrin signaling through Rho/PI 3-kinase. Dev Biol. 2007;302:256-266.

2. Rios H, Koushik SV, Wang H, et al. periostin null mice exhibit dwarfism, incisor enamel defects, and an early-onset periodontal disease-like phenotype. Mol Cell Biol. 2005;25:11131-11144.

3. Ruan K, Bao S, Ouyang G. The multifaceted role of periostin in tumorigenesis. Cell Mol Life Sci. 2009;66:2219-2230.

4. Gillan L, Matei D, Fishman DA, Gerbin CS, Karlan BY, Chang DD. Periostin secreted by epithelial ovarian carcinoma is a ligand for $\alpha_{V} \beta_{3}$ and $\alpha_{V} \beta_{5}$ integrins and promotes cell motility. Cancer Res. 2002;62:5358-5364.

5. Kudo Y, Ogawa I, Kitajima S, et al. Periostin promotes invasion and anchorageindependent growth in the metastatic process of head and neck cancer. Cancer Res. 2006;66:6928-6935.

6. Puglisi F, Puppin C, Pegolo E, et al. Expression of periostin in human breast cancer. J Clin Pathol. 2008;61:494-498.

7. Sasaki H, Dai M, Auclair D, et al. Serum level of the periostin, a homologue of an insect cell adhesion molecule, as a prognostic marker in nonsmall cell lung carcinomas. Cancer. 2001;92:843-848.

8. Sasaki H, Lo KM, Chen LB, et al. Expression of periostin, homologous with an insect cell adhesion molecule, as a prognostic marker in non-small cell lung cancers. Jpn J Cancer Res. 2001;92:869-873.

9. Sasaki H, Yu CY, Dai M, et al. Elevated serum periostin levels in patients with bone metastases from breast but not lung cancer. Breast Cancer Res Treat. 2003;77:245-252.

10. Shao R, Bao S, Bai X, et al. Acquired expression of periostin by human breast cancers promotes tumor angiogenesis through up-regulation of vascular endothelial growth factor receptor 2 expression. Mol Cell Biol. 2004;24:3992-4003.

11. Siriwardena BS, Kudo Y, Ogawa I, et al. Periostin is frequently overexpressed and enhances invasion and angiogenesis in oral cancer. Br J Cancer. 2006;95: 1396-1403.

12. Wong GS, Lee JS, Park YY, et al. Periostin cooperates with mutant p53 to mediate invasion through the induction of STAT1 signaling in the esophageal tumor microenvironment. Oncogenesis. 2013;2:e59.

13. Michaylira CZ, Wong GS, Miller CG, et al. Periostin, a cell adhesion molecule, facilitates invasion in the tumor microenvironment and annotates a novel tumorinvasive signature in esophageal cancer. Cancer Res. 2010;70:5281-5292.

14. Wong GS, Habibollahi P, Heidari P, et al. Optical imaging of periostin enables early endoscopic detection and characterization of esophageal cancer in mice. Gastroenterology. 2013;144:294-297.

15. Wong GS, Rustgi AK. Matricellular proteins: priming the tumour microenvironment for cancer development and metastasis. Br J Cancer. 2013;108:755-761.

16. Zhu M, Saxton RE, Ramos L, et al. Neutralizing monoclonal antibody to periostin inhibits ovarian tumor growth and metastasis. Mol Cancer Ther. 2011;10: 1500-1508.

17. Davis MA, Reynolds AB. Blocked acinar development, E-cadherin reduction, and intraepithelial neoplasia upon ablation of p120-catenin in the mouse salivary gland. Dev Cell. 2006;10:21-31.

18. Stairs DB, Bayne LJ, Rhoades B, et al. Deletion of p120-catenin results in a tumor microenvironment with inflammation and cancer that establishes it as a tumor suppressor gene. Cancer Cell. 2011;19:470-483.

19. Turker NS, Heidari P, Kucherlapati R, Kucherlapati M, Mahmood U. An EGFR targeted PET imaging probe for the detection of colonic adenocarcinomas in the setting of colitis. Theranostics. 2014;4:893-903.

20. Heidari P, Wehrenberg-Klee E, Habibollahi P, Yokell D, Kulke M, Mahmood U. Free somatostatin receptor fraction predicts the antiproliferative effect of octreotide in a neuroendocrine tumor model: implications for dose optimization. Cancer Res. 2013;73:6865-6873.

21. Heidari P, Deng F, Esfahani SA, et al. Pharmacodynamic imaging guides dosing of a selective estrogen receptor degrader. Clin Cancer Res. 2015;21: 1340-1347.

22. Orecchia P, Conte R, Balza E, et al. Identification of a novel cell binding site of periostin involved in tumour growth. Eur J Cancer. 2011;47:2221-2229. 